The International Journal Of Engineering And Science (IJES)

|| Volume || 6 || Issue || 1 || Pages || PP 01-04 || 2017 ||

ISSN (e): $2319-1813 \operatorname{ISSN}$ (p): $2319-1805$

\title{
A review: Morphological, physiological, biochemical and molecular plant responses to water deficit stress
}

\author{
Ayed Sourour ${ }^{1 *}$, Othmani Afef ${ }^{1}$, Rezgui Mounir $^{2}$, Ben Younes Mongi ${ }^{1}$ \\ ${ }^{1}$ University of Carthage, Field Crop Laboratory, Regional Research Development Office of Agriculture in Semi \\ Arid North West of Kef, Tunisia \\ ${ }^{2}$ University of Carthage, Science and Agronomic Techniques Laboratory, National Agricultural Research \\ Institute of Tunisia, Rue Hédi Karray 2049 Ariana, Tunisia.
}

\begin{abstract}
-
In the conditions of changing climate, plants are continuously subject to several biotic and abiotic stresses. Among these stresses, drought is one of the most severe abiotic stress which threats crops production and yield. Crops demonstrate various morphological, physiological, biochemical and molecular responses under water stress. This review describes some aspects of drought induced changes in morphological, physiological, biochemical and molecular changes in plants. Drought triggers a wide variety of plant responses, ranging from cellular metabolism to changes in growth development including roots, shoots and final yield. Moreover, understanding the biochemical and molecular responses to drought is essential for perception of plant resistance mechanisms to water-limited conditions. The sections of this review deal with plant responses including root growth, transpiration, photosynthesis, phenotypical flexibility, accumulation of solutes and expression of some genes and proteins for improving the tolerance to the drought stress.
\end{abstract}

Keywords: adaptation, drought, yield

Date of Submission: 12 December 2016

Date of Accepted: 05 January 2017

\section{INTRODUCTION}

Crop yield reduction, as a consequence of increasingly severe climatic change, threatens food security. Plant growth is highly influenced by environmental stresses. Resistance to stresses is a complex task which make difficult to find an observable genetic correlation between a morphological, physiological traits and yield performance under field conditions. Abiotic stresses, including water deficit, salinity and extreme temperatures, are the most important to be considered in the selection of new genotypes because it affects crop production. Among these stress, drought is one of the most adverse factors of plant growth and productivity [1]. There are different types of plant reactions to this stress: (i) stress escape (ii) stress avoidance; and (iii) stress tolerance. Drought stress is a very complex character depending on severity, duration of the stress event, and the plant growth stage. Plant drought tolerance involves changes at whole-plant functions. For these reasons, it is necessary to determine the most suitable conditions in which to observe the type of response that is better in order to improve plant performance. Water stress induces many physiological, biochemical and molecular response on plants. Moderate to severe water stress affects various morpho-physiological traits such as chlorophyll fluorescence, water use efficiency and dry matter yield, water content and water potential membrane stability $[2,3]$ and pigment content stability $[4,5,6]$. Drought stress progressively reduces CO2 assimilation rates owing to decrease stomatal conductance. It affects leaf size, stems extension and root proliferation, troubles plant water relations and decreases water-use efficiency. It disrupts photosynthetic pigments and reduces the gas exchange and the production of active oxygen species causes a decrease in plant growth and productivity. This review focuses on the ability and strategies of plants to respond and adapt to drought stress.

\section{AGRO-MORPHOLOGICAL PLANT RESPONSE TO DROUGHT STRESS}

Drought stress is an important environmental limiting factor at the juvenile stage of plant growth and establishment. In fact, seed germination is the first stage of growth that is sensitive to water deficit. Therefore, germination of seeds, vigour and coleoptile length are crucials for the establishment of plants. Visible syndromes of plant subject to water deficit in the vegetative phase are leaf wilting, a decrease in plant height, number and area of leaves and delay in formation of buds and flowers [7]. In fact, limitation of leaf growth is among the earliest visible impacts of water stress because leaves determine radiation interception and are the main photosynthetic organs [8]. Water deficit stress mostly reduced leaf water potential and growth and in turn the leaf areas in many species and leaf senescence could be observed under severe water stress $[9,10,11]$. In 
fact, development of optimal leaf area is important to photosynthesis and dry matter yield. According to Lonbani and Arzani [12], leaf extension can be reduced under drought environment in order to get a balance between the water status of plant tissues and the water absorbed by plant roots [13]. In addition, Blum [14] suggested that a small leaf area is beneficial under drought stress in order to avoid hydratation. Moreover, water availability is priliminary sensed by roots affects roots growth and root system architecture (root length, spread, number, and length of lateral roots) $[15,16]$. Roots are essential for plant functions and productivity, such as water and nutrient uptake, forming symbioses with other microorganisms in the rhizosphere. Thus, a prolific root system can confer the advantage to support accelerated plant growth during the early crop growth stage and extract water from soil [17]. Drought stress reduced the number of days to heading, peduncle length and plant fresh and dry biomass production [10,18]. Peduncle length has been also suggested as useful indicator of yield performance in stress conditions. Kaya et al. [19] have been found a positive correlation between peduncle length and grain yield. Water stress affects also yield and its related traits such as number of spike per $\mathrm{m}^{2}$, grain per spike number, 1000 grain weight and grain weight per spike particularly in arid and semi-arid regions [20]. The effect of deficit water on yield and its yield components at different growth stages have been noted by several authors [21]. In fact, drought stress may occur throughout the growing season, early or late season, yield is reduced mostly when water stress occurs during the heading or flowering phases but its effect on yield reduction is highest when it occurs after anthesis. Drought stress can reduce 17 to $70 \%$ of grain yield in the case of the durum wheat [22]. During maturity, this stress resulted in about $10 \%$ decrease in yield but moderate stress during the early vegetative growth has mainly no effect on yield [23].

\section{PhysiologiCAl PLANT RESPONSE TO WATER STRESS}

The mainly effect of drought is limiting photosynthesis through stomatal closure which limits $\mathrm{CO} 2$ uptake by leaves and prevent the transpirational water loss as result to the reduction in leaf turgor and/or water potential [24, 25]. The limitation CO2 availability causes the photo-damage [26]. Drought stress suppress particularly photochemical efficiency of photosystem PS II by decreasing electron transport, removal of external proteins, and release of calcium and magnesium ions from their binding [27, 28]. Very severe drought conditions reduce photosynthesis due to a decrease in Rubisco activity [29]. The activity of the photosynthetic electron transport chain is finely tuned to the presence of $\mathrm{CO}_{2}$ in the chloroplast and change in photosystem II under drought conditions.Drought stress produced changes in the ratio of chlorophyll ' $a$ ' and ' $b$ ' and carotenoids [10]. Chlorophyll concentration has considered as an index for evaluation of source. In fact, resistant cultivar to water stress had high chlorophyll content [30]. In this context, Ashraf et al. [31] found that drought stress reduced concentration of chlorophyll b more than chlorophyll a.

Water stress causes also the reduction of relative water content [32, 33]. In fact, high relative water content is a resistant mechanism to drought and is related to more osmotic regulation or less elasticity of tissue cell wall [34].The osmotic adjustment is the process of accumulation of solutes in response to water stress by maintaining turgor in tissues. Solutes accumulate contributed to osmotic adjustment in plants, include inorganic cations, organic acids, carbohydrates and free amino acids. In some plants potassium is the primary inorganic cation accumulating during water stress and it is often the most abundant solute in leaf $[35,36]$.

Osmotic adjustment depends highly on photosynthesis to supply compatible solute. As dehydration becomes more severe, photosynthesis is inhibited, resulting in smaller solute supply for osmotic adjustment. With continued water limitation, osmotic adjustment delays, but cannot completely prevent, dehydration [37]. Osmotic adjustment is not permanent and plants often respond rapidly to reduce presence of water. Osmoregulation and turgor maintenance permit continued root growth and efficient uptake of soil moisture [38]. However, despite the accumulation of ions and organic solutes, allowing osmotic adjustment in the meristematic and expanding regions, growth of the shoot may still be inhibited by stress, either because osmotic adjustment may not be sufficiently rapid to compensate for growth or due to a stress induced fall in turgor.

\section{BIOCHEMICAL DERIVATIONS OF DROUGHT TOLERANCE}

Drought induces important alterations in plant biochemistry and metabolism. Under drought stress, the responses deal with the production of reactive oxygen species (ROS) which cause membrane injuries, protein degradation, enzyme inactivation and thus induce oxidative stress [39].

Under water deficit conditions, the accumulation of ABA hormone plays a great role in response and tolerance to dehydration. Closure of stomata and induction of the expression of multiple genes involved in defense against the drought stress are functions of ABA. The amount of ABAs in xylem saps increases substantially under reduced water availability in the soil, and this results in an increased ABA concentration in different compartments of the leaf. Another well-known effect of drought in plants is the decrease in PM-ATPase activity. Low PM-ATPase increases the cell wall $\mathrm{pH}$ and lead to the formation of ABA- form of abscisic acid. ABA- cannot penetrate the plasma membrane and translocate toward the gourd cell by the water stream in the leaf apoplasm. High ABA concentration around guard cell results in stomata closure and help to keep water. 
Under water stress conditions, plants synthesize alcohols, sugars, proline, glycine, betaine and putrescine and accumulate solutes [40,41]. Dehydrins have been the most observed group among the accumulated proteins in response to loss of water and increased in barley and maize under water stress. LEA proteins plays important role as protection of plants. Osmotin is also an accumulated protein under water stress in several plant species such as tobacco, triplex, tomato and maize [42]. Moreover, accumulation of proline in plant tissues is considered as an indicator of tolerance to drought stress. In this context, it is reported that proline content in resistant wheat cultivars was more than in sensitive cultivar under the drought stress. Soluble carbohydrates accumulation has also a role in osmotic regulations and conservation mechanism [43].Lipids, one of the major components of plant membrane, are affected by water stress. In plant cell, polar acyl lipids are the main lipids associated with membraneous structures [44]. Glycolipids (GL) are found in chloroplasts membranes (more than 60\%) and phospholipids (PL) are thought to be the most important mitochondrial and plasma membrane lipids [45].

\section{MOLECUlar RESPONSES}

The understanding of molecular reponses of plants to abiotic stresses involved the development of new tools via genetic manipulation by expression of several stress induced genes. A number of different types of proteins are likely to function to improve stress tolerance. Genes encoding the enzymes of osmolyte biosynthesis permit the synthesis of these osmotic compounds in response to stress. Proline is synthesized from 1-glutamic acid through D1-pyrroline-5-carboxylate (P5C) by two enzymes: P5Csynthetase and P5Creductase. Proline dehydrogenase and $\mathrm{P} 5 \mathrm{Cdehydrogenase}$ are the enzymes that degrade proline to l-glutamic acid. In response to water deficit, P5Csynthetase is induced and proline dehydrogenase is repressed, resulting in a net accumulation of proline. Another class of genes, which may be unique to plants, is induced in plants subjected to water deficit. These genes called the late embryogenesis abundant genes, abbreviated as lea genes, are also developmentally programmed for expression in desiccating seeds. These genes encode small hydrophilic proteins that are predicted to protect proteins and membranes when cellular dehydration occurs. In the case of wheat, there are several genes which are responsible for drought stress tolerance and produce different types of enzymes and proteins for instance, late embryogenesis abundant (lea), responsive to abscisic acid (Rab), rubisco, helicase, proline, glutathione-S-transferase (GST), and carbohydrates during drought stress [46].

In this approach the simultaneous analysis of a great number of genes is possible, and all the studies based on data indicating that several genes are involved in the modulation of plant adaptation to environmental stresses. However, there is the need to further analyze plant stress response at molecular level due to the complexity of events associated with the sensing of stress and the activation of specific pathways. This complexity is even greater when a combination of different stresses such as heat and drought is simultaneously applied.

\section{CONCLUSION}

Water deficit affects the development, growth and yield in plant crop, but the tolerance crops to this stress varies remarkably. Changes in morphological, physiological, biochemical and molecular aspects are generally noted in response to drought stress. Understanding these responses to drought is important for screening tolerance of genotypes to water-limited conditions.

\section{REFERENCES}

[1]. Noorka I. R. and Tabasum S, Dose-Response Behaviour of Water Scarcity Towards Genetical And Morphological Traits In Spring Wheat (Tricticum Aestivum L.) Pak. J. Bot., 47(4): 2015, 1225-1230.

[2]. Sairam. R. K., Deshmukh, P. S., Shukla, D. S. and Ram, S, Metabolic activity and grain yield under moisture stress in wheat genotypes. Indian Journal of Plant Physiology, 33, 1990, 226-231.

[3]. Gholamin R., Khayatnezhad M, Effects of Polyethylene Glycol and $\mathrm{NaCl}$ Stress on Two Cultivars of Wheat (Triticum durum) at Germination and Early Seedling Stages. American-Eurasian J. Agric. \& Environ. Sci., 9 (1): 2010, 86-90

[4]. Ehdaie, B., Hall, A.E., Farquhar, G.D., Nguyen, H.T. and Waines, J.G., Water-use efficiency and carbon isotope discrimination in wheat. Crop Sci., 31: 1991, 1282-1288.

[5]. Keyvan S, The effects of drought stress on yield, relative water content, proline, soluble carbohydrates and chlorophyll of bread wheat cultivars. J. of Animal and Plant Sci., 8(3): 2010, 1051-1060.

[6]. Datta J.K., Mondal T., Banerjee A., Mondal N.K., Assessment of drought tolerance of selected wheat cultivars under laboratory condition. Journal of Agricultural Technology 7: 2001, 1383-393.

[7]. Bhatt, R.M. and N.K. Srinivasa Rao, Influence of pod load response of okra to water stress. Indian J. Plant Physiol., 10: 2005, 54 59

[8]. Taleisnik E, Rodriguez AA, Bustos D, Erdei L, Ortega L, Senn ME, Leaf expansion in grasses under salt stress. Journal of Plant Physiology 166, 2009, 1123-1140.

[9]. Wullschleger S, Loewith R, Oppliger W, Hall MN, Molecular organization of target of rapamycin complex 2. J Biol Chem 280(35): 2005, 30697-704.

[10]. Farooq, M., A. Wahid, N. Kobayashi, D. Fujita and S.M.A. Basra, Plant drought stress: effects, mechanisms and management. Agron.Sustain. Dev., 29: 2009, 185-212

[11]. Luo,H.H., Zhang, Y.L and Zhang, W.F., Effect of water stress and rewatering on photosynthesis, root activity, and yield of cotton with drip irrigation under mulch. Photosynthetica Volume 54, issue 1, 2016, 65-73

[12]. Lonbani, M. and Arzani A, Morpho-physiological Traits Associated with Terminal Drought Stress tolerance in Triticale and Wheat. Agric. Res., 9: 2011, 315-329. 
[13]. Passioura, J.B., Drought and drought tolerance. Plant Growth Regul. 20, 199 ,79-83.

[14]. Blum, A., Mitigation of drought stress by crop management. Available at: 200 5. www.PlantStress.com.

[15]. Blum A., Crop responses to drought and the interpretation of adaptation. Plant Growth Regulation Volume 20, Issue 2, 1996,135148

[16]. Salazar C., Hernández C., and Teresa P.M. A review. Plant water stress: Associations between ethylene and abscisic acid response. Chilean Journal of Agricultural, 2015. Research 75 (Suppl. 1).

[17]. Smith, S. and De Smet, I., Root system architecture: insights from Arabidopsis and cereal crops. Philos. Trans. R. Soc. Lond. B 367, 2012, 1441-52

[18]. Kiliç, H. and T. Yağbasanlar., The effect of drought stress on grain yield, yield components and some quality traits of durum wheat (Triticum turgidum ssp. durum) cultivars. Not. Bot. Hort. Agrobot. Cluj 38 (1): 2010, 164-170

[19]. Kaya C., Higgs D., Saltali K., Gezeral O. Response of strawberry grown at high salinity and alkalinity to supplementary potassium. J. PLANT. NUTR. 25(7): 2002, 1415-1427

[20]. Bilal M, Iqbal I, Rana RM, Shoaib Ur Rehman, Haidery Q-ul-A, Ahmad F, Ijaz A \& Umar HMI A comprehensive review of effects of water stress and tolerance in wheat (Triticum aestivum L.). Tropical Plant Research 2(3): 2015, 271-275

[21]. Simane, B., P.C. Struik, M.M. Nachit, and J.M. Peacock. On to genic analysis of field components and yield stability of durum wheat in water-limited environments. Euphytica 71: 1993, 211-219

[22]. Ehdaie, B. Variation in water use efficiency and its components in wheat. II. Pot and field experiments. Crop Sci. 35: 1995, 16171626

[23]. Bauder, J., Irrigation with Limited Water Supplies. Montana State University, Communications Services. Montana Hall. Bozeman, 2001, MT 59717. USA.

[24]. Yokota A., Kawasaki S., Iwano M., Nakamura C., Miyake C., Akashi K., Citrulline and DRIP-1 Protein (ArgE Homologue) in Drought Tolerance of Wild Watermelon, Ann. Bot. 89, 2002, 825-832.

[25]. Anjum F., Yaseen M., Rasul E., Wahid A., Anjum S., Water stress in barley (Hordeum vulgare L.). I. Effect on chemical composition and chlorophyll contents. Pakistan J. Agr. Sci. 40, 2003, 45-49.

[26]. Cornic G., Massacci, A., Leaf photosynthesis under drought stress, in: Baker N.R., (Ed.), Photosynthesis and the Environment. The Netherlands 1996:Kluwer Academic Publishers,

[27]. Barta C, Dunkle AM, Wachter RM, Salvucci ME., Structural changes associated with the acute thermal instability of Rubisco activase. Arch Biochem Biophys 499: 2010, 17-25

[28]. Zlatev Z. and Lidon F.C.,. An overview on drought induced changes in plant growth, water relations and photosynthesis. Emir. J. Food Agric., 24, 2012,57-72.

[29]. Bota J, Medrano H, Flexas J. Is photosynthesis limited by decreased Rubisco activity and RuBP content under progressive water stress? New Phytologist. 2004;162:671-681

[30]. Sairam R.K., Shukla D.S., Saxena D.C., Stress induced injury and antioxidant enzymes in relation to drought tolerance in wheat genotypes. Biologia Plantarum, 40: 1997, 357-364.

[31]. Ashraf, M.Y., A.R. Azmi, A.H. Khan and S.A.Ala. Effect of water stress on total phenols, Peroxidase activity and chlorophyll content in wheat. Acta physiologiae plantarum. 16(3): 1994, 185-191.

[32]. Cornic G. Drought stress inhibits photosynthesis by decreasing stomatal aperture — not by affecting ATP synthesis. Trends in Plant Science 5: 2000, 187-188.

[33]. Saeidi M., Ardalani S., Jalali-Honarmand S., Ghobadi M.E., Abdoli M., Evaluation of drought stress at vegetative growth stage on the grain yield formation and some physiological traits as well as fluorescence parameters of different bread wheat cultivars. Acta Biologica Szegediensis Volume 59(1): 201,535-44

[34]. Ritchie, S.W., Nguyan, H.T.and Holaday. A.S., leaf Water content and gas exchange parameters of two wheat genotypes differing in drought resistance. Crop sci.30: 1990, 105-111.

[35]. Jones, M. M., Osmond, C. B. and Turner, N. C., Accumulation of solutes in leaves of sorghum and sunflower in response to water deficits. Aust. J. Plant Physiol., 7: 1980, 193-205.

[36]. Ford, C. W. and Wilson, J. R., Changes in levels of solutes during osmotic adjustment to water stress in leaves of four tropical pasture species. Aust. J. Plant Physiol., 8: 1981,77-91.

[37]. Kramer, P. J. and Boyer, J. S., Water relations of plants and soils. Academic Press.San Diego, 1995.

[38]. Sharp, R. E. and Davies, W. J., Solute regulation and growth by roots and shoots of water-stressed maize plants. Planta, 147: 1979, 43-49.

[39]. Zlatev, Z. and F.C. Lidon. An overview on drought induced changes in plant growth, water relations and photosynthesis. Emir. J. Food Agric. 24, 2012, 57-72.

[40]. Chopra, R.K., Sinha, S. K., Prospects of success of biotechnological approaches for improving tolerance to drought stress in crop plants. Curr. Sci., 74 (1): 1998, 25-34.

[41]. Galston, A. W. and Sawhney, R. K., Polyamines in plant physiology. Plant Physiol., 94: 1990, 406-410.

[42]. Ramagopal, S., Advances in understanding the molecular biology of drought and salinity tolerance in plants- the first decade. Adv. Pl. Biotech. Biochem., (Eds.) M.L. Lodha, S.L. Mehta, S. Ramagopal and G.P. Srivastava, Indian Society of Agriculture Biochemists, Kanpur, India, 1993,pp. 39-48

[43]. Martin, G.B., Brommonschenkel, S.H., Chunwongse, J., Frary, A., Ganal, M.W., Spivey, R., Wu, T., Earle, E.D., and Tanksley, S.D. Map-based cloning of a protein kinase gene conferring disease resistance in tomato. Science 262, 1993, 1432-1436

[44]. Harwood, J. L., The synthesis of acyl lipids in plant tissues. Prog Lipid Res., 18: 1979, 55-86.

[45]. Harwood, J. L., Plant acyl lipids. In: P.K. Stumpf, ed. The Biochemistry of Plants. Vol 4. New York: Academic Press, pp. 1980, 155 .

[46]. Bray E. A., Plant Response to Water-deficit Stress. Encyclopedia Of Life Sciences Nature Publishing Group 2001/www.els.net 